\title{
With appreciation to Dr Angelo Pietrobelli, IJO Pediatric Associate Editor and pediatric obesity pioneer
}

\author{
Richard L. Atkinson $\mathbb{1}^{1,2} \cdot \operatorname{lan}$ A. Macdonald ${ }^{1,2}$
}

Received: 6 April 2020 / Revised: 14 April 2020 / Accepted: 20 April 2020 / Published online: 12 May 2020

(c) Springer Nature Limited 2020

The editors, associate editors, and editorial staff of the International Journal of Obesity (IJO) would like to extend our thanks to Angelo Pietrobelli, M.D., for his long service to IJO as an Associate Editor for Pediatrics. Dr. Pietrobelli is retiring as of March, 2020, after 17 years in this position.

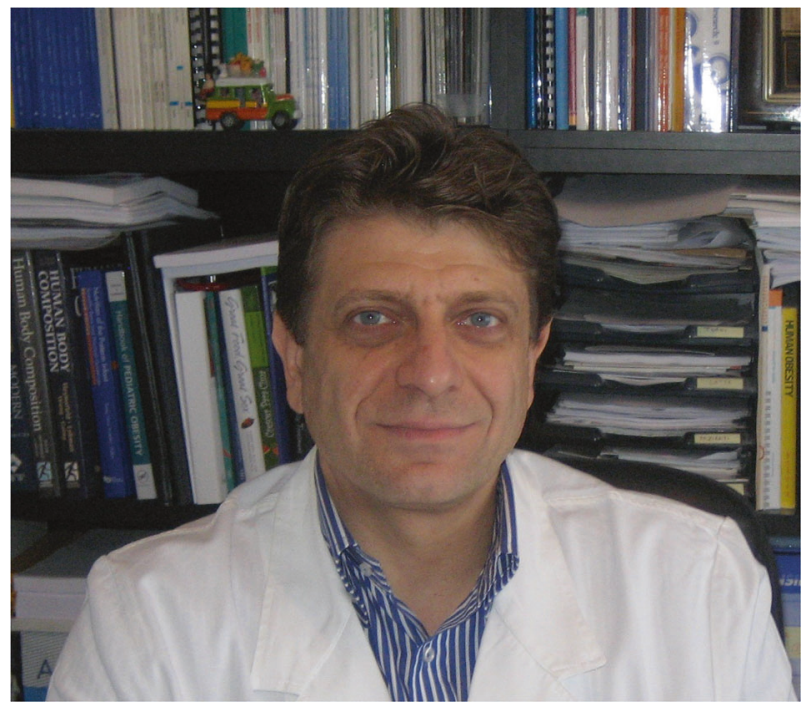

In 2004, there were no journals that were devoted to the area of Pediatric Obesity as the publishing world had concluded that there were not enough manuscripts to justify a journal solely about Pediatric Obesity. However, the editors of IJO noted that an increasing percentage of submitted manuscripts dealt with Pediatric Obesity, so IJO decided to create the position of Pediatric Associate Editor to help handle this influx. Dr Pietrobelli of the University of Verona, Italy, and Dr Kate

Richard L. Atkinson

ADV36lab@Gmail.com

1 Department of Internal Medicine, Virginia Commonwealth University, Richmond, VA, USA

2 University of Nottingham, Nottingham, UK
Steinbeck of the University of Sydney, Australia, were the founding Pediatric Associate Editors at IJO. Shortly after he was appointed, Dr Pietrobelli suggested the idea that collections of excellent Pediatric Obesity articles could be put together and published periodically in IJO. This led to the creation of the IJO Pediatric Highlights issues that were to be published four times per year and featured on the cover of the journal and on the website. For the first time investigators in Pediatric Obesity had a journal focused on the area, and the number of manuscripts submitted to $I J O$, and specifically in the area of Pediatric Obesity, increased dramatically. For a number of years $I J O$ was the place to go for Pediatric Obesity manuscripts. Later, specific journals devoted to Pediatric Obesity were started but IJO has continued as a major source of high-quality publications in the field.

In addition to his long service to $I J O$, Dr Pietrobelli should be recognized as one of the pioneers in the field of Pediatric Obesity. He received his M.D. degree from the University of Bologna in 1992 and continued there for his internship and residency in Pediatrics. He obtained specialized training in Pediatric Endocrinology at the University of Milan, then came to Columbia University College of Physicians \& Surgeons in New York, USA. He served as a Postdoctoral Research Scientist at The Obesity Research Center, St. Luke's/Roosevelt Hospital, where he specialized in Pediatric Obesity research under the direction of Dr Steven Heymsfield. He participated in some of the early investigations of pediatric body composition, particularly the use of dual-energy X-ray absorptiometry, and became an expert in assessment of pediatric adiposity. After leaving New York he returned to the University of Verona where he rose to the rank of Professor of Pediatrics and Nutrition. He has been highly productive during his career, having over 250 publications in the medical literature.

We will regret no longer working with Dr Pietrobelli at IJO and we wish him the very best in his career in the future. His long years of service to $I J O$ and to the field of Pediatric Obesity will serve as an inspiration for the current Pediatric Associate Editors and to young investigators in the field. 